\title{
Supply chain management diffusion among firms in the Republic of Ireland
}

The changing business environment has sharpened the focus on the need for robust approaches to supply chain management (SCM) and the improvement of supply chain capability and performance. This is particularly the case in Ireland, which has the natural disadvantage of a location peripheral to significant markets and sources of raw materials which results in relatively high transport and distribution costs. Therefore, in order to gain insights into current levels of diffusion of SCM, a survey was conducted among 776 firms in the Republic of Ireland. The empirical results suggest that there is a need for more widespread adoption of SCM among Irish firms. This is particularly the case in relation to the four main elements of SCM excellence reported on in this paper. The design of supply chain solutions is a highly skilled, knowledge-intensive and complex activity, reflected in a shift from "box moving" to the design and implementation of customised supply chain solutions. Education and training needs to be addressed by stimulating the development of industry-relevant logistics and SCM resources and skills.

Keywords: Supply chain management; logistics; adoption; diffusion; Republic of Ireland

\section{Introduction}

The changing business environment has sharpened the focus on the need for robust approaches to supply chain improvement. Supply chain management (SCM) is widely recognised to be important to business in general, and to business in Ireland in particular.

Ireland has a natural disadvantage as a result of its peripheral location, which results in higher transport and distribution costs. However, transport is only one - and often not the most significant - element of the total cost of moving product through the supply chain, i.e. the chain that starts with the purchasing of raw materials or products for resale, through production, warehousing and finally, distribution to the customer. Higher transport costs can be traded off against, for example, lower levels of inventory or better customer service. In this way the total cost of the supply chain, rather than any one single cost element (e.g. transport) can be optimised.

Excellence in SCM can therefore offset the physical disadvantage posed by Ireland's geographic location by securing benefits elsewhere in the wider supply chain. In order to gain unique insights into current levels of adoption of SCM in Irish businesses, a comprehensive survey has been undertaken. A total of 776 Irish firms, randomly selected from established industrial databases across all sectors in the Republic of Ireland, participated (see NITL, 2006).

This paper reports some of the main findings of the survey. Following this introduction the paper goes on to provide an overview of the key characteristics of SCM excellence and their relevance to Irish industry based on a comprehensive literature review. Based on this overview, details of the methodology adopted and the data collection are presented. The paper concludes with a discussion of the findings with specific reference to the need for more widespread adoption of SCM philosophy.

\section{Excellence in Supply Chain Management}

It is appropriate to refer to the seminal article by Mentzer et al. (2001), in particular to two constructs proposed by the authors. Firstly, they suggest that many definitions of SCM are trying to define two interdependent but different concepts in one term. The first is referred to as supply chain orientation (SCO) and is defined as the recognition by an organisation of the systemic, strategic implications of the tactical activities involved in managing the various flows in a supply 
chain'. However, SCM requires that SCO exists in several linked companies across a supply chain. In other words, SCO is a prerequisite for SCM. Secondly, the definition of SCM proposed by the authors based on their analysis of the literature is:

The systemic, strategic coordination of the traditional business functions and the tactics across these business functions within a particular company and across businesses within the supply chain, for the purposes of improving the long-term performance of the individual companies and the supply chain as a whole.

This definition amalgamates a variety of concepts and philosophies into a single sentence. Its authors claim that their work 'should help practitioners as well as researchers to understand SCM, to give guidance to what SCM is, its prerequisites, and its potential effects on business and supply chain performance'.

It is worth noting that SCM is not new. The term may be relatively new but supply chains have existed for a very long time - in fact they have probably always existed! For example, Forrester's often cited article from the Harvard Business Review in 1958 (Forrester, 1958) states that:

Management is on the verge of a major breakthrough in understanding how industrial company success depends on the interactions between the flows of information, materials, money, manpower, and capital equipment. The way these five flow systems interlock to amplify one another and to cause change and fluctuation will form the basis for anticipating the effects of decisions, policies, organisational forms, and investment choices.

His article introduced the demand amplification concept using a computer simulation model. If, as Forrester suggested, management was on 'the verge of a major breakthrough' almost half a century ago, it seems pertinent to raise questions concerning how this breakthrough - mainly in relation to managing relationships between supply chain companies - has impacted on companies in reality. In fact over 40 years after Forrester's article first appeared, Mentzer et al. (2001), in concluding their paper, ask the specific question: 'How prevalent is SCM?' This is a key question to which ongoing research needs provide some answers. This paper does so in the specific context of the adoption of 'World Class' SCM practices by firms in the Republic of Ireland.

Identifying some of the characteristics in evidence in companies that might be regarded as world class provides a useful starting point for this discussion. 'World Class' in this context means companies that have been successful in tough, competitive international markets over a sustained period of time. By definition, it is impossible to develop an exhaustive list of the characteristics of SCM excellence but the following four elements appear to be of critical importance for most companies in most sectors (see Figure 1):

(1) Identification and measurement of customer service: understanding customer service requirements in the market sets the specification for supply chain design (see, for example, Korpela et al., 2001).

(2) Integration of supply chain activities: many supply chain non-value adding activities (NVAs) are caused by fragmented supply chain configurations. In this context the authors define an NVA as 'any activity (or resource or asset) that adds cost (or time) to any supply chain process without adding value from a customer perspective' (based on Jones et al.,1997; Goldrat and Cox, 1992; Womack and Jones, 2003; and others). 
(3) SCM as a senior management function: SCM is becoming regarded more widely as a primarily strategic activity (see, for example, Gattorna et al., 2003).

(4) Establishment and measurement of supply chain key performance indicators (KPIs): a robust performance measurement system provides a rational basis for continuous improvement (see, for example, Sweeney, 2007).

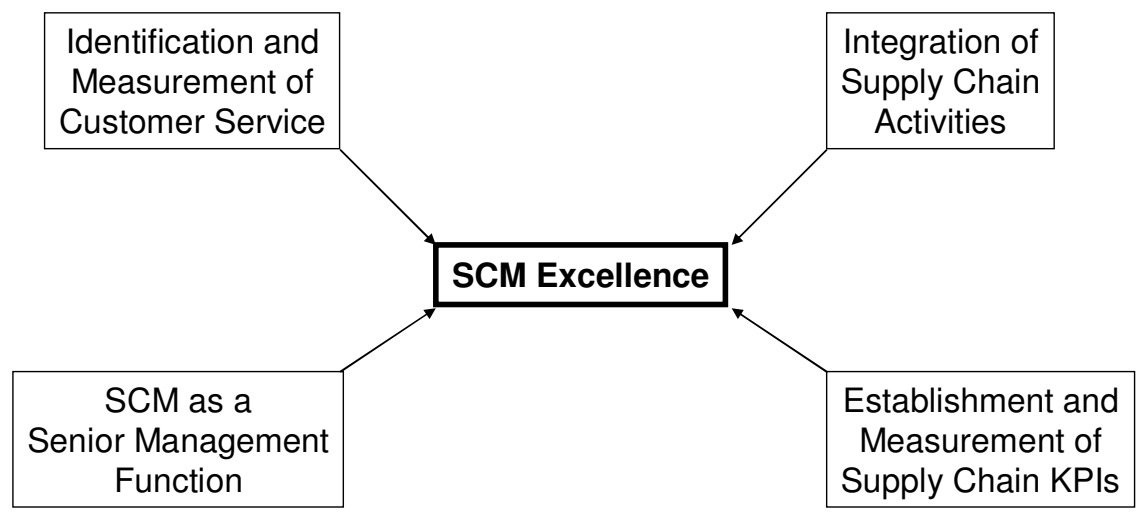

Figure 1. Elements of SCM Excellence

Customer service has long been recognised as an integral component of a firm's marketing strategy to increase sales and profits (Lambert, 1992). Furthermore, customer service is becoming a key source of differentiation or an order winning criterion in many sectors (Christopher, 2005). In many sectors the importance of customer service relative to product quality (now largely an order qualifier) and price (largely determined by the dynamics of supply and demand in the market and subject to downward pressure in many sectors) has increased (Sweeney, 2004). In other words, the role of customer service as an element of the overall marketing mix of organisations has become more improtant. The key to the role of customer service in SCM lies in: (i) understanding customers' needs and requirements in targeted markets/segments; and then, (ii) meeting (or exceeding) these needs. To support this, the concept of an external and internal audit has been suggested (Sterling and Lambert, 1989). The title of the paper by Korpela et al. (2001) - 'Customer service based design of the supply chain' - captures this approach very effectively.

From an examination of both the historical evolution and the many available definitions of SCM it is evident that the concept of integration lies at the heart of SCM philosophy (see, for example, Christopher, 1992; New, 1996, Lambert, 2004). Cooper et al. (1997) specifically described SCM as 'an integrative philosophy'. The work of Fawcett and Magnan (2002) identified four levels of integration in practice.

1. Internal cross-functional integration;

2. Backward integration with valued first-tier suppliers;

3. Forward integration with valued first-tier customers; and,

4. Complete backward and forward integration ('from the supplier's supplier to the customer's customer').

The first of these relates to integration of activities and processes which are carried out within a single organisation. The others describe varying degrees of integration of activities which span 
the boundaries of organisations, with the last one being viewed as the theoretical ideal. The phrase internal supply chain has appeared in the literature (Huin, et al, 2002) to describe work aimed at breaking down the barriers between functions within organisations. This shift from away from a functional orientation towards a more company-wide focus is in line with the SCO approach of Mentzer et al. (2001) in the sense that SCO at firm level, as manifested in high levels of internal integration, could be regarded as a pre-requisite for SCM, as manifested in high levels of external integration. Monczka et al. (1998) refer to the use of, 'a total systems perspective across multiple functions and multiple tiers of suppliers'. The reference to 'multiple functions' alludes to internal integration; extending this to 'multiple tiers of suppliers' introduces the external integration concept, albeit in the rather limited sense of backward integration with suppliers. As noted earlier, the theoretical ideal is complete backward and forward integration ('from the supplier's supplier to the customer's customer'). The widely cited work of Bowersox et al. (1999) describes a framework of six competencies (the Supply Chain 2000 Framework) that lead to world class performance in logistics and SCM. These competencies, all of which are concerned with integration, are grouped into three areas: operational, planning and relational. The work of Mollenkopf and Dapiran (1999) and Carranza et al. (2002) used this framework to assess logistics strategies in Australia/New Zealand and Argentina respectively.

The strategic role of SCM in achieving market differentiation, and the resultant need for senior management commitment to SCM, is widely referred to in the literature (see, for example, Lambert et al., 1998). Min and Mentzer (2004) state that 'top management support, which includes leadership and and commitment to change, is an important antecedent to SCM and the absence of it is a barrier'. The strategic role of SCM is a strong theme in the work of Gattorna and his collaborators (see, for example, Gattorna et al., 2003). He argues that empirical evidence is mounting to suggest that if organisations are to achieve sustained high levels of financial and operating performance, dynamic alignment of four key elements (the competitive environment, company strategy, culture and leadership style) must exist. Alignment in this context includes the development of a leadership style at the executive level to ensure the appropriate sub-cultures are in place as required.

The need for continuous innovation and improvement in all aspects of a company's supply chain has long been recognized. Standing still means falling behind in today's increasingly competitive market places. Effective performance measurement provides companies with the only rational basis for continuous improvement (Gunasekaran et al., 2004). As world class companies have experienced, external and internal supply chain performance measurement is the primary mechanism for organisational learning at all levels. Furthermore, supply chain learning - based on firm-to-firm exchange of knowledge - is based on leveraging the supply chain as a mechanism to enable learning and competence development (Bessant et al., 2003; Sweeney et al., 2005). A Learning Organisation is an organisation which recognises the importance of this type of learning, and which has developed practices which reflect this. Similarly, a Learning Supply Chain is a supply chain which takes learning seriously at all levels and which bases its learning initiatives on its performance measurement system. The successful supply chains of the future will be those which are agile. A key ingredient of agility is the ability to learn and to respond quickly to changing market and other requirements. In this context, the organisational learning that effective supply chain performance measurement delivers will become even more important (van Hoek et al., 1998). Finally, the importance of effective measurement is reflected in one of 
the six competencies incorporated into the Supply Chain 2000 Framework (Bowersox et al., 1999 ) - it is referred to as measurement integration.

\section{The Republic of Ireland and SCM}

The Republic of Ireland is a small, open, trade-dependent economy and has been one of the fastest growing economies in the developed world for some time. Over the last decade, unprecedented economic growth has seen the level of Irish real gross domestic product (GDP) almost double in size. The Irish economy has been transformed from being agrarian and traditional manufacturing based to one increasingly based on the hi-tech and internationally traded services sectors. In 2003, the services sector accounted for $66 \%$ of employment, industry for $28 \%$ and agriculture for $6 \%$.

There have been many reasons advanced for Ireland's success, which in combination can help explain the exceptionally strong growth rates experienced (Layte et al., 2005). They include European Union (EU) membership and access to the Single Market; a high proportion of the population of working age; increased participation in the labour market especially by females; a reversal of the trend of emigration toward immigration; sustained investment in education and training; relatively low corporation tax rates and a large multinational presence; coordinated social partnership agreements and a more stable public finance position.

In the context of supply chain management (SCM), the openness of the Irish economy is reflected both in the international mobility of its labour and capital and high levels of foreign direct investment (FDI). Ireland's share of global and EU FDI has risen sharply in recent years. From just under $4 \%$ of the total in 2000, Ireland accounted for more than one twelfth of total inflows to the EU-15 in 2003. On a global basis, the rate of increase was similar, reaching almost $5 \%$ of total world inflows (Forfas, 2005). The US was the biggest source of FDI in 2003 with flows from that source estimated at approximately $€ 8 \mathrm{bn}$. or $25 \%$ of the total. In terms of stocks of FDI, UNCTAD (2004) records a figure for Ireland equivalent to 127\% of GDP in 2003 (\$193bn.). In absolute terms, this is the sixth highest level among the EU-15 and by far the largest in per capita terms.

However, in relation to manufacturing there is evidence that significant amounts of (mainly labour intensive) activity has in recent years migrated eastwards to lower labour cost locations mainly in Eastern Europe and parts of Asia (ESG, 2004). There is also a growing realisation that in the medium term, Ireland's ability to hold its position as the location of choice for FDI in Europe is under threat because of its high cost base.

A number of other issues combine to make logistics and SCM particularly critical from an Irish perspective. As noted earlier, the country's relatively peripheral location results in transportation costs for companies based in Ireland being higher than those in more favourable locations (Forfas, 1995). Furthermore, recent changes in the corporate taxation regime (in particular the introduction of a $12.5 \%$ tax rate on service businesses) makes the option of companies establishing business units (profit centres) in Ireland with responsibility for the management of supply chain activities more attractive. One of the necessary skills will therefore be the ability of Irish business to manage increasingly complex supply chains. Excellence in SCM can offset the physical disadvantage posed by Ireland's geographic location by securing improvements elsewhere in the wider supply chain. 


\section{Methodology}

A pre-tested survey instrument was sent to the sample frame of 1,655 companies (both large multinationals as well as small and medium sized indigenous companies), randomly selected from established industrial databases across all sectors in Ireland (see NITL, 2006). The target respondent within each company was the person with overall responsibility for SCM. This included Managing Directors, SCM or Logistics Directors/Managers and others ${ }^{1}$. Questionnaire testing was carried out using two mechanisms. Firstly, a focus group comprising research staff at the author's institute was formed and it evaluated the questionnaire on a section by section basis. This resulted in the removal, rewording and addition of a number of questions, as well as some minor restructuring. Secondly, three companies were interviewed using the modified questionnaire. This comprised one company from each of the following categories: food and consumer products, industrial products and international services. This part of the testing resulted in further minor changes being incorporated into the questionnaire.

'Warming letters' were sent to potential respondents offering the summary of the results by way of an incentive. After several follow-ups by phone, the response was increased to 766 organisations (i.e. a response rate of $47 \%$ ). This response rate can be considered very satisfactory in comparison to other similar survey research. The survey was conducted over an 8 month period from the time of initial contact to beginning of the analysis. The surveys were tested for statistically significant differences in the responses of early and late returned surveys. No significant differences were found, suggesting that the sample is representative of the population.

Table 1 shows the characteristics of the sample frame. 85\% of the sample are small and medium size enterprises (SMEs) and 70\% are indigenous firms. The food and consumer sector represents $26 \%$ of the total sample, industrial products represent $45 \%$, and international services $28 \%{ }^{2}$.

Table 1. Sample Characteristics

\begin{tabular}{|l|r|r|}
\hline Number of Employees by Firm & Number & Percent \\
\hline Less than 10 & 105 & $13.6 \%$ \\
\hline From 10 to 19 & 134 & $17.4 \%$ \\
\hline From 20 to 49 & 192 & $24.9 \%$ \\
\hline From 50 to 249 & 117 & $15.2 \%$ \\
\hline 250 and more & & \\
\hline & & \\
\hline Company Ownership & 540 & 69.6 \\
\hline Irish company & 212 & $27.3 \%$ \\
\hline $\begin{array}{l}\text { Subsidiary of company with HQ outside of } \\
\text { Ireland }\end{array}$ & & \\
\hline
\end{tabular}

\footnotetext{
${ }^{1}$ See Figure 5 for details.

${ }^{2}$ Food and consumer sectors include: food, drink and tobacco, agriculture, wood/furniture, consumer products and FMCG. Industrial products include: manufacturing, electronics, automotive, fabricated metals and engineering, construction and construction materials, textiles and leather, printing and paper, chemicals and pharmaceuticals, rubber plastics, packaging, oil. International services include: software services, other traded services, transport, logistics and distribution, medical and health, telecoms, business services and consultancy, financial services, publishing, port and shipping and entertainment, film, media and music.
} 


\begin{tabular}{|l|r|r|}
\hline Semi-state/government/co-op & 21 & $2.7 \%$ \\
\hline Other & 3 & $0.4 \%$ \\
\hline Business Sector & & \\
\hline Food and Consumer & & \\
\hline Industrial Products & 198 & $25.5 \%$ \\
\hline (International) Services & 346 & $44.6 \%$ \\
\hline Other & 215 & $27.7 \%$ \\
\hline
\end{tabular}

\section{Selected Key Results and Discussion}

The survey assessed the level of adoption SCM practices in relation to a wide range of factors. These factors included demand forecasting, procurement and purchasing practices, warehouse management, inventory control, transport and distribution operations, production control and technology usage. The results reported in this paper relate specifically to the four characteristics of SCM excellence identified in the literature review (see section 2 above) ${ }^{3}$.

\subsection{Identification and measurement of customer service}

The results revealed that $48 \%$ of companies have not adopted KPIs for customer service to date. Furthermore, those firms that do measure customer service formally tend to use quite limited measures (see Figure 2).

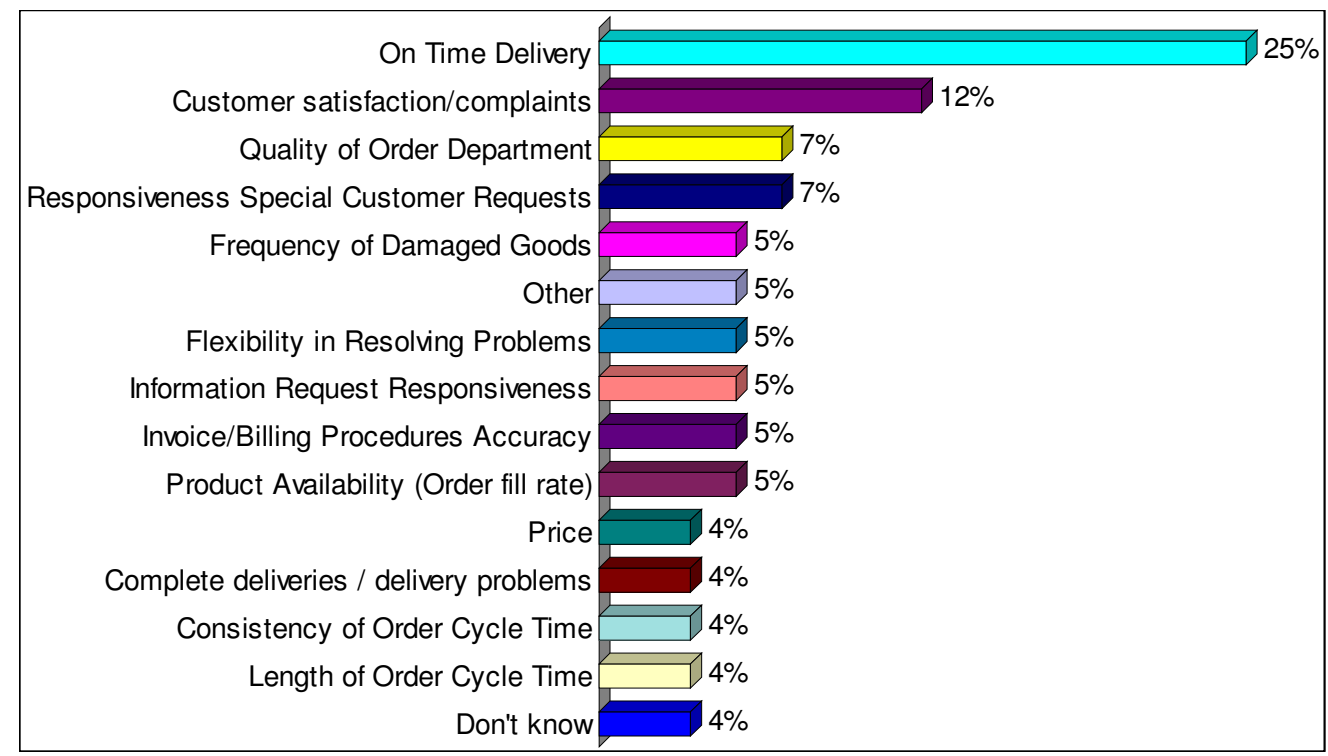

Figure 2. Main indicators used for customer service

\footnotetext{
${ }^{3}$ Further analysis can be found in NITL(2006).
} 
The ability of a firm's supply chain to perform consistently depends above all on its ability to continuously monitor market dynamics in terms of customer service requirements. This is particularly the case in the growing number of markets and market segments characterised by ever increasing levels of competition. Lack of knowledge and understanding of changing market conditions clearly limits the ability of organisations to improve overall levels of supply chain capability and performance. As a result, the findings of this research in relation of the measurement of customer service requirements in Irish firms inevitably presents serious systemic issues which need to be addressed.

Further analysis of the findings revealed significant differences across sectors and between firms of different sizes. This indicates that the need for improvement, and the scope of this potential improvement, is greatest in smaller firms and in sectors which have traditionally been later adopters of innovation.

\subsection{Integration of supply chain activities}

A fundamental principle of SCM is the development of collaborative and partnership relationships throughout the supply chain, including with customers and suppliers. The survey used Likert scales to assess the degree of perceived SCM integration as well as the extent of customer and supplier involvement. This method provided feedback that is more expansive than close-ended questions but easier to quantify than open-ended questions. Figure 2 shows the extent to which respondents perceived various supply chain activities to be integrated internally. Whilst some activities (e.g. customer service and sales order processing) appear to be quite well integrated elements of overall SCM within the majority of firms, others (notably inbound transport, new product introduction and demand forecasting) are less well integrated.

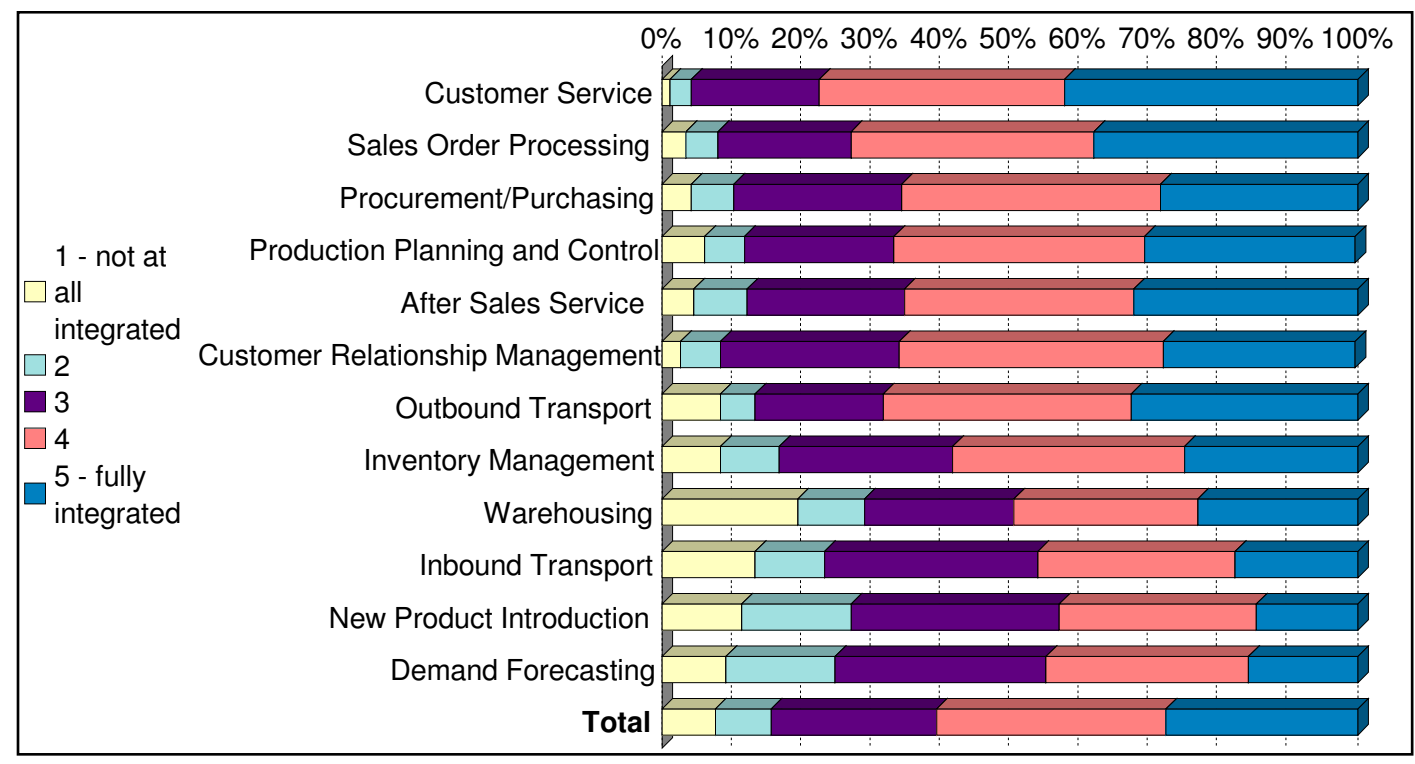

Figure 3. Perceived Integration of Supply Chain Activities 
Another indication of the degree of supply chain integration in firms relates to the extent of customer and supplier involvement in supply chain activities. The data reported in Figure 3 indicates that this varies widely with a small minority of respondents reporting 'very strong' involvement by customers and suppliers in any of the activities considered.

Extent of customer involvement

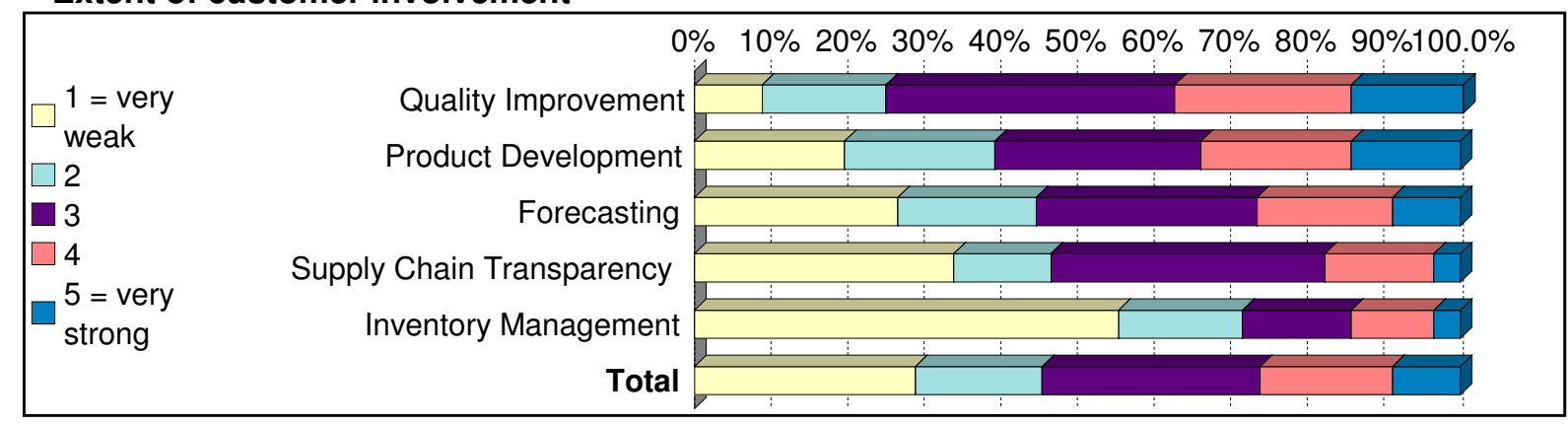

Extent of supplier involvement

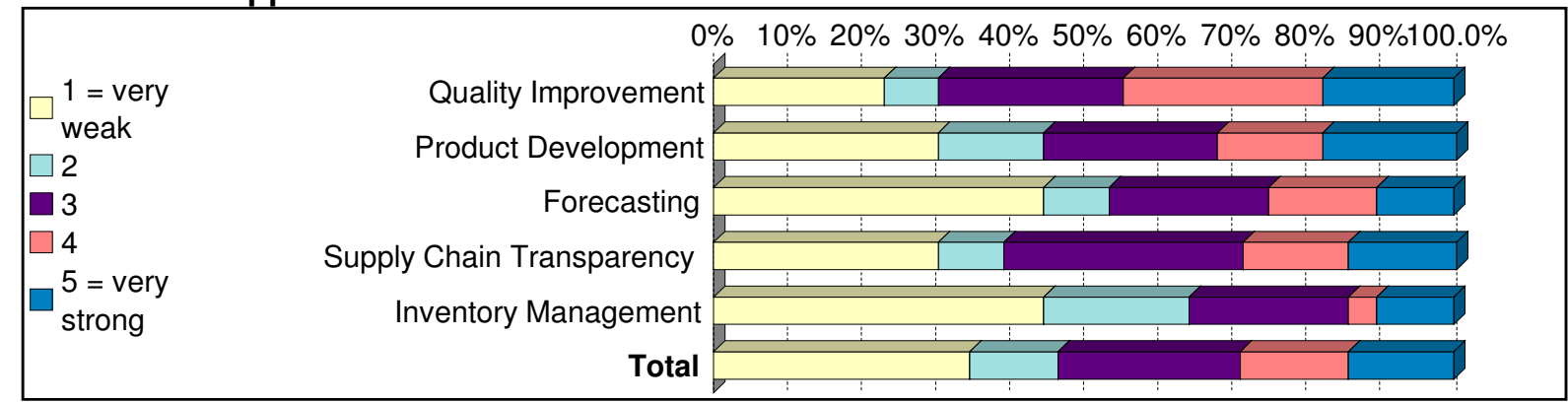

Figure 4. Extent of Customer and Supplier Involvement in Supply Chain Activities

These findings suggest that moves towards higher levels of both internal and external supply chain integration have been carried out in - at best - a tactical and piecemeal fashion rather than as a matter of strategic priority. There is evidence from the findings of reasonably high levels of $\mathrm{SCO}$ in terms of recognition of the need for more holistic management of internal material and information flows. However, this does not appear to be translating widely into meaningful levels of systemic and strategic coordination of supply chain activities across businesses within the wider supply chain. For example, in relation to inventory management less than a quarter of firms indicate that it is 'fully integrated' into overall firm SCM. In terms of external integration, only $3 \%$ report a 'very strong' level of customer involvement in inventory management, with less than $10 \%$ indicating a 'very strong' level of supplier involvement.

\subsection{SCM as a senior management function}

The survey assessed the organisation of SCM activities. In relation to overall responsibility for SCM activities, Figure 4 indicates that only $8.8 \%$ of companies have a specialised SCM or logistics manager. 


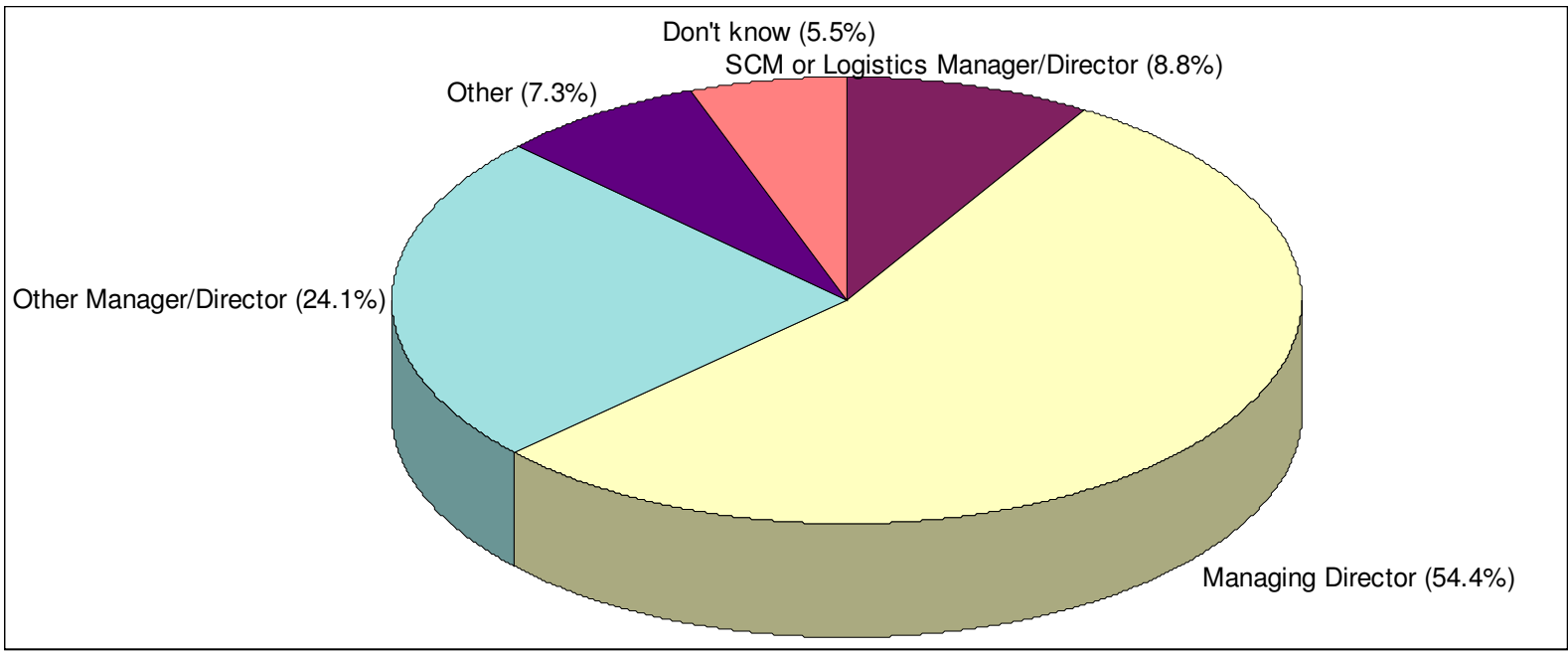

Figure 5. Responsibility for supply chain management

The authors recognise that different approaches to supply chain organisation are appropriate in different firms and that the development of the optimum approach at any point in time depends on a wide variety of inter-related and interdependent factors. It would be inappropriate to propose an ideal organisational configuration irrespective of a company's products, processes and culture. Nonetheless, whilst recognising that every company has unique products, processes and culture, the increasing strategic importance of SCM across a range of sectors in not in dispute (as noted in section 2 above). The lack of specific SCM and logistics positions at a senior within Irish firms is an indication that the strategic nature of the subject has not been embraced by the great majority of firms.

Ongoing qualitative studies by the authors based on the results of this survey are aimed at gaining further insights into these issues. Initial analysis of this work indicates that within those firms where SCM is the responsibility of the managing director or chief executive, SCM is not widely regarded as a strategic activity with marketing and finance related activities assuming greater priority and consuming more management time. Further work is needed to explore these and other related issues in more detail.

\subsection{Establishment and measurement of supply chain key performance indicators (KPIs)}

The survey indicated that few companies have clearly defined supply chain KPIs. For example, as reported earlier $46 \%$ of companies do not have KPIs for customer service. Furthermore, 59\% of companies did not know their total supply chain costs. In relation to the measurement of performance of specific supply chain activities, $82 \%$ of companies do not formally measure warehouse performance in terms of KPIs. There were similar findings in relation to the management of procurement, production and transportation activities.

As noted in section 2 (above), it is difficult to approach the task of supply chain improvement in any rational manner in the absence of information about current levels of performance. In other words, the generation of any meaningful improvements is predicated upon the very existence of robust and integrated systems of KPIs. The lack of such systems in Irish firms clearly compromises their ability to put such improvements into place. 


\section{Research Limitations and Implications}

The focus of the research described in this paper relates primarily to companies based in Ireland. It provides a baseline for future research on developments in SCM practice. It is limited in terms of direct comparability with practices in other countries, identifying drivers and inhibitors of SCM diffusion and understanding the relationship between adoption of SCM practice and competitive advantage.

There have been a limited number of comparable studies carried out in other countries. However, the situation in Australia and New Zealand (ANZ) presented by Mollenkopf and Dapiran (2005) is noteworthy in our context as a result of some similarities in relation to the logistical challenges resulting from relative geographical peripherality and demographic factors. In relation to customer service, they found that firms that emphasise service (as opposed to cost) have higher levels of logistics and SCM competency. Furthermore, a relatively small percentage of respondents (18\%) adopt strategies which focus on true supply chain integration. This mirrors some of the findings reported in Ireland (see section 5.2). Similarly, 25\% of firms indicated that they had a position with the term supply chain in the title. As noted in section 5.3, 8.8\% of Irish firms have specialised logistics or supply chain managers. A study focused on SCM practices in SMEs by Quayle (2003) found that less than 3\% of companies in Wales (again with some similar logistical challenges to Ireland) have a senior executive responsible for SCM. In relation to performance measurement, the focus of the ANZ study is on benchmarking rather than internal measurement making direct comparisons impossible. However, the majority of ANZ firms (64\%) benchmark customer service performance while only 54\% of Irish firms have even internal KPIs in this area (see section 5.4). This suggests that practice in Irish firms is seriously lagging in this area.

Future research on SCM diffusion in Ireland needs to build on the baseline which has been established by the research described in this paper. However, ideally it needs to adopt a framework which enables better international comparisons to be made while continuing to recognise some of the key unique characteristics of the Irish landscape.

Having established a baseline, future research will focus on how SCM diffusion will evolve. However, there is also a need to gain insights into the factors which act as drivers and enablers of good practice, as well as those which act as inhibitors. Qualitative research methodologies would be well suited to developing this deeper understanding. In addition, further research is needed to better understand the relationship between SCM adoption and competitive advantage. The work of Bowersox et al. (1999) describing a framework of six competencies that lead to world class performance in logistics and SCM provides a useful point of departure for this work.

\section{Conclusions: The Need for Wider SCM Diffusion}

The pressures imposed and opportunities afforded by globalisation, the open nature of the Irish economy and recent developments in information technology mean that SCM has a critical role to play in both the medium and long term. Looking over the horizon, one of the keys to industrial success for any country will be its managerial competence in advanced SCM skills. This is especially true of developed economies such as Ireland where there is an increasing trend to outsource lower function manufacturing processes to lower cost locations but to retain high skill functions - such as research, design, marketing and sales - at the primary base. 
The findings from the survey indicate that, in general terms, while pockets of SCM undoubtedly exist (particular in larger companies and in certain sectors) there is significant room for improvement in the great majority of firms. This is particularly the case in relation to the four main elements of SCM excellence reported on in this paper. The design of supply chain solutions is a highly skilled, knowledge-intensive and complex activity, reflected in a shift from "box moving" to the design and implementation of customised supply chain solutions. Education and training needs to be addressed by stimulating the development of industry-relevant logistics and SCM resources and skills.

Making companies aware of SCM and developing the necessary internal capability is essential for Ireland's industrial base in order to minimise the impact of peripherality, enable smaller firms to take advantage of global supply chain opportunities and to exploit the opportunities which exist to manage virtual supply chain configurations from locations in Ireland.

\section{References}

Bessant J., Kaplinsky R. and Lamming R., 2003. Putting supply chain learning into practice, International journal of operations \& production management, 23 (2), 167-184.

Bowersox, D.J., Closs, D.J. and Stank T.P., 1999. 21st century logistics : making supply chain integration a reality, CLM, Oak Brook, IL.

Carranza, O., Maltz, A. and Antun, J.P., 2002. Linking logistics to strategy in Argentina, International journal of physical distribution \& logistics management, 32 (6), 480-496.

Christopher, M.,1992. Logistics and supply chain management: strategies for reducing costs and improving service. London: Pitman.

Christopher, M., 2005. Logistics and supply chain management: creating value-adding networks London: FT Prentice Hall.

Cooper, M.C., Ellram, L.M., Gardner, J.T., and Hanks, A.M., 1997. Meshing multiple alliances, Journal of business logistics, 18 (1), 67-89.

Enterprise Strategy Group (ESG), 2004. Ahead of the curve. Dublin: Forfas.

Fawcett S. E. and Magnan G. M., 2002. The rhetoric and reality of supply chain integration International journal of physical distribution \& logistics management, 32 (5), 339-361.

Forfas, 2005. International trade and investment report 2004. Dublin: Forfas.

Forfas, 1995. World class to serve the world. Dublin: Forfas.

Forrester, J. W.,1958. Industrial dynamics: a major breakthrough for decision makers. Harvard business review, 38 (Jul._Aug.), 37-66. 
Gattorna, J, Ogluin, R and Reynolds M.W., 2003. Handbook of supply chain management. $5^{\text {th }}$ ed. London: Gower.

Goldratt, E. M. and Cox, J.,1992. The goal: a process of ongoing improvement. New York: North River Books.

Gunasekaran, A. Patel, C. and McGaughey, R.E., 2004. A framework for supply chain performance measurement, International journal of production economics, 87 (3), 333-347.

Huin, S.F., L.H.S. Luong, L.H.S. and Abhary, K., 2002. Internal supply chain planning determinants in small and medium-sized manufacturers, International journal of physical distribution \& logistics management, 32 (9), 771-782.

Jones, D. T., Hines, P. and Rich, N.,1997. Lean logistics. International journal of physical distribution \& logistics management, 27 (3/4), 153-173.

Korpela, J., Lehmusvaara, A. and Tuominen, M., 2001. Customer service based design of the supply chain. International journal of production economics, 69 (2), 193-204.

Lambert, D., 1992. Developing a customer-focused logistics strategy. International journal of physical distribution \& logistics management, 22 (6), 12-19.

Lambert, D.M., 2004. Supply chain management Chapter 1 in Lambert, D.M. (Ed.), Supply chain management: processes, partnerships, performance, Sarasota, FL: Supply Chain Management Institute., 1-23.

Lambert, D.M., Cooper, M.C., and Pagh, J.D., 1998. Supply Chain Management: implementation issues and research opportunities, International journal of logistics management, 9 (2), 1-19.

Layte, R., O'Connell, P.J., Fahey, T. and McCoy, S., 2005. Ireland and economic globalisation: the experiences of a small open economy in Blossfeld, H., Klijzing, E., Kurz, K. and Mills, M., eds. Globalisation, uncertainty and youth in society. New York: Routledge.

Mentzer, J. T., DeWitt, W., Keebler, J. S., Min, S., Nix, N. W., Smith, C. D. and Zacharia Z. G., 2001. Defining supply chain management. Journal of business logistics, 22 (2), 1-25.

Min, S. and Mentzer, J.T., 2004. Developing and measuring supply chain management concepts, Journal of business logistics, 25 (1), 63-99.

Mollenkopf, D. and Dapiran, G.P., 2005. The importance of developing logistics competencies: a study of Australian and New Zealand firms, International journal of logistics: research \& applications, 8 (1), 1-14.

Monczka, R., Trent, R. and Handfield, R., 1998. Purchasing and supply chain management Cincinnati: South-Western College Publishing. 
National Institute for Transport and Logistics (NITL), 2006. Competitive challenges: chain reactions. An analysis of supply chain management and competitive solutions for the island of Ireland, Dublin: NITL.

Quayle, M., 2003. A study of supply chain management practice in UK industrial SMEs, Journal of supply chain management: an international journal, 8 (1), 79-86.

Sterling, J. and Lambert, D., 1989. Customer service research: past, present and future, International journal of physical distribution \& materials management, 19(2), 1-23.

Sweeney, E., 2004. Making supply chain management work for you!, Logistics solutions, 7(4), 21-25.

Sweeney, E., 2007. Supply chain benchmarking and performance measurement: towards the learning supply chain in Sweeney, E., ed. Perspectives on supply chain management and logistics, Dublin: Blackhall Publishing, 283-294.

Sweeney, E., Evangelista, P. and Passaro, R,. 2005. Putting supply chain learning theory into practice: lessons from an Irish case, International journal of knowledge and learning, 1 (4), 357372.

United Nations Conference on Trade and Development (UNCTAD), 2004. Handbook of statistics, Geneva: UNCTAD.

van Hoek, R.I., 1998. Measuring the unmeasurable - measuring and improving performance in the supply chain, Supply chain management: an international journal, 3(4), 187-192.

Womack, J. P. and Jones, D. T., 2003. Lean thinking: banish waste and create wealth in your corporation, 2nd edition. London: Free Press. 